\title{
Difficult trade-offs in response to COVID-19: the case for open and inclusive decision making
}

\author{
We argue that deliberative decision making that is inclusive, transparent and accountable can contribute to more \\ trustworthy and legitimate decisions on difficult ethical questions and political trade-offs during the pandemic \\ and beyond.
}

\author{
Ole F. Norheim, Joelle M. Abi-Rached, Liam Kofi Bright, Kristine Bærøe, Octávio L. M. Ferraz, \\ Siri Gloppen and Alex Voorhoeve
}

T he COVID-19 pandemic has forced governments to make difficult choices that profoundly affect the health, wealth and freedoms of their populations. To deal with the public health and economic emergencies generated by COVID-19, these high-stakes decisions have often been made quickly, with little involvement of stakeholders in the deliberation about which policies to pursue. Given the uncertain duration of the pandemic, and even as vaccines are in the process of being approved, there are important moral, legal and practical reasons to engage in open and inclusive decision-making processes. These include an improvement in the quality of decisions, an increase in legitimacy and trust, compliance with legal obligations and improved adherence to restrictions on behavior that are necessary to curb the spread of the virus. Such deliberative processes also respect people's abilities to offer, appreciate and act on reasons and are required by human rights and rule of law principles. To serve their purpose and build public trust, these processes should be institutionalized rather than ad hoc, thus making inclusive, transparent and accountable decision making a routine feature of governance, now and beyond the pandemic. We argue the case for such open and inclusive decision making, characterize it and offer examples of how to put it into practice.

\section{What is at stake}

Despite considerable uncertainty about the health impacts of COVID-19, the scientific consensus is that the health burdens of uncontrolled spread are substantial ${ }^{1}$. In the absence of policies to lessen its spread, it is likely that in excess of $50 \%$ of countries' populations would be infected ${ }^{2}$. Infection fatality rate (IFR) estimates vary and depend on country characteristics, including demography, but are estimated to be in the order of $0.23-1.15 \%{ }^{3}$, suggesting that the direct effects of uncontrolled spread would be COVID-19 deaths in the order of $0.1-0.6 \%$ of the population, concentrated among the elderly, vulnerable, socioeconomically disadvantaged and marginalized groups ${ }^{4}$. Moreover, for many, non-fatal infections present a substantial health burden, and the burden of caring for those with COVID-19 could overwhelm the health system.

To limit infections, governments have turned to general or targeted lockdowns coupled with public health messaging, testing and contact tracing. These policies have a complex cluster of effects. An early, well-executed lockdown can be highly effective at limiting the direct health effects of COVID-19. But this limits liberties and can have negative effects on short-term economic growth, access to social services, employment, sociability, mental well-being and education. It is feared the combined effect of lockdowns and economic disruption due to illness could wipe out important gains made in the past decade in terms of poverty reduction and lifespan, worsening the quality of life in the affected countries while widening income inequality. The World Bank estimates that as many as 150 million people may be pushed into extreme poverty due to the economic consequences of the pandemic ${ }^{5}$. Moreover, if not well executed, recurrent lockdowns and other restrictive public health measures can cause 'pandemic fatigue' and social unrest, especially in fragile countries already at war or facing other crises.

Therefore, while countries face dilemmas involving the best balance between health on the one hand and income, liberties, education and further goods on the other, the nature of these trade-offs depends on the country and the context of the policy. These factors include speed, stringency and comprehensiveness of public measures, public health capacity, level of income and inequality, population age distribution and public attitudes. The impacts are likely to be diverse across and within countries and are further complicated by the presence of extensive uncertainty about the impact of policies and their sustainability in the face of mounting costs.

Some governments' use of emergency powers in response to COVID-19 has side-lined, challenged and weakened democratic processes. The pandemic has exposed and widened existing social inequalities and divisions. Trust in political and scientific authorities is eroding. At the same time, trust in public authorities and among community members has emerged as a decisive factor in the ability of many countries to secure compliance with pandemic regulations and measures. As a consequence, many countries have started to critically review the way they make decisions and who should make them, both in the remaining period of this pandemic and in preparation for future health emergencies. In the remainder of this Comment, we present the case for making these decisions in a transparent and inclusive manner.

\section{Elements of open and inclusive decision making}

For policies to be effective, they must be based on accurate knowledge and adherence to public health recommendations. Policy decisions have an impact on the distribution of risks and benefits and create benefits and burdens ${ }^{6}$. For people to willingly abide by them when this is burdensome, policies must be perceived as fair, and open and inclusive decision making contributes to this perception. This general framework is supported by political philosophy and socio-legal research on procedural fairness $^{7-10}$. The essential arguments for and features of transparent and inclusive decision making are listed in Box 1 and involve participation of political leaders, experts and all affected parties. 
Box 1 | Open, inclusive decision-making under COVID-19

\section{(I) Supporting reasons}

Political equality and human rights

- Inclusive decision making ensures that governments act according to the rights of political participation enshrined in national and international law, particularly human rights law and the principles of accountable government.

- Broad-based, transparent decision making fulfills the ideal of procedural fairness, which requires that decisions that affect peoples' interests be taken: (i) on the basis of evidence; (ii) with equal consideration of everyone's interests and perspectives; (iii) on the basis of reasons that people can share; (iv) in an open, accessible manner; and (v) through institutional means that permit challenge and revision of decisions.

- Inclusive decision making rests on the democratic ideal that all people should have a fair opportunity to participate in decisions that affect them.

- Inclusion of all those affected promotes self-esteem and mutual respect.

- Transparency allows the public to form informed opinions.

- When decisions are based on reasons that can be appreciated by all, such as the importance of protecting health and incomes, all participants are treated as capable of understanding and acting on those common reasons.

- Procedurally fair decision-making processes contribute to trust in decision makers and to the legitimacy of the decisions.

- Inclusive decision making may lessen social disagreement, because even in the face of polarized opinions about what to do it may be possible to achieve agreement on fair procedures for arriving at policy decisions. Policies resulting from fair procedures may then be accepted even by those who disagree with them on substantive grounds.

- Restrictions on freedom are more readily accepted if they are the outcome of a fair process. Acceptance reduces the burden of restrictions and renders them more consistent with autonomy.

Scrutiny and communication

- Policy decisions are better targeted and more effective if they are informed by accurate descriptions of the circumstances and evidence of what works.

- Critical scrutiny of evidence and uncertainty can improve decisions.

- Communication of clear rationales and uncertainty, and making evidence publicly accessible prevents disinformation and builds trust.

\section{Trust and adherence}

- Open, inclusive decision making builds trust. This improves adherence to policies, making them more effective. Greater effectiveness, in turn, engenders more trust in policy makers. Open decision making can therefore contribute to a virtuous cycle of increasing trust, adherence and policy effectiveness.

(II) Key elements

Political leaders

- Decision making is built on evidence.

- The ethical, legal, scientific, economic, social and political reasons for a decision are made transparent.

- To facilitate consensus, as far as possible, these reasons are shared by people with dissimilar moral and political outlooks.

- Decisions and their rationales are communicated in a manner that everyone can understand.

Experts

- Experts are drawn from a variety of fields, including the humanities, medical and social sciences.

- Experts communicate transparently about what works and for whom and about uncertainty and values.

- Experts publish their findings and recommendations for critical scrutiny.

- Epidemiological, statistical and other relevant data are open access.

- Experts participate in fora that leave them open to critical feedback and adjust those elements of their practice that are legitimately challenged by members of the public.

The public

- All affected parties are included, listened to and have a say.

- Special attention is given to vulnerable and marginalized groups and to the harms and benefits to people who cannot easily raise their voices.

\section{Accountability}

- All affected individuals and groups can challenge decisions.

- Mechanisms are in place for feedback and revision when new challenges or evidence emerge.

- The input of affected parties is documented.

- Mechanisms are in place for budgetary transparency and ensuring that loans and grants are allocated appropriately.

\section{Fair process}

Fairness can be seen in terms of the decision itself (substantive fairness) or in terms of how the decision is made (procedural fairness), or both ${ }^{7}$. The assumption behind procedural fairness is that even though there may be widespread disagreement about what would be a just distribution of burdens and benefits, the affected parties may be expected to reach an agreement on what conditions must be in place to make the decision-making process fair. In general, procedural fairness requires that decisions affecting people's interests are made (i) on the basis of available evidence; (ii) in a way that gives equal consideration to everyone's interests and takes account of their perspectives; (iii) based on reasons that people can share, that is, recognize as relevant from their differing views of the good life and of substantive fairness; (iv) in an open and accessible manner; and (v) through institutional means that permit challenge and revision of decisions. Fair procedures promote inclusion, require transparency and make the decision makers accountable, which can contribute to perceived legitimacy and trust in the decision makers and adherence to resulting policies ${ }^{11}$.
Transparent, inclusive and accountable decision making is not simply something desirable from the perspective of ethics and efficiency. It is also required by human rights and rule of law principles that most countries have committed to respect through participation in international treaties and provisions of their own domestic laws, including constitutions. The right to directly and indirectly participate in political and public life is recognized in the Universal Declaration of Human Rights (article 21) and the International Covenant on Civil and Political Rights (article 25), among other places. Participation rights 


\section{Box 2 | Practical examples}

Countries with established systems of participatory health governance benefit from a base of public trust. Together with effective communication strategies and unified public health systems, these systems are central to a successful response to COVID-19. Examples include New Zealand, Taiwan and South Korea ${ }^{22}$.

Elements of systems for open and inclusive decision making include the following:

(i) Inclusive deliberative bodies: ad-hoc citizens' assemblies, permanent citizens' panels, advisory councils:

- Australia: COVID-19 Culturally and Linguistically Diverse Community Forums in South Australia ${ }^{23}$

- England: Citizens' Panel Planning the West Midlands' Recovery ${ }^{23}$
- USA: Oregon Citizens' Assembly on COVID-19 Recovery

(i) Hearings: mandated in law or optional:

- France: Commission d'enquête pour l'évaluation des politiques publiques face aux grandes pandémies à la lumière de la crise sanitaire de la COVID-19 et de sa gestion ${ }^{24}$

- Norway: Corona-law and regulation hearings

- USA: National Academies of Sciences Engineering and Medicine Public Comment Opportunities: Discussion Draft of the Preliminary Framework for Equitable Allocation of COVID-19 Vaccine ${ }^{25}$

(i) Open, self-selective public participation mechanisms: town halls, village meetings (face to face or online), radio and television call-in programs, petitions and crowdsourcing, initiated by either government or civil society.

- Brazil: mechanism for transparency and public engagement on COVID-19 in the federal health system ${ }^{26}$

- France: Citizens' committee in Grenoble $^{27}$

- Lebanon: Independent Committee for the Elimination of COVID-19 ${ }^{28}$

- Scotland: Coronavirus (COVID-19): National crowd-sourcing exercise ${ }^{23}$

- Senegal: several citizens' initiatives ${ }^{29}$

- United Kingdom: Independent SAGE $^{30}$

- United States: Connecting to Congress, deliberative town halls on COVID-19 and Endcoronavirus.org are also inextricably linked to other human rights such as the rights to peaceful assembly and association, freedom of expression and opinion and the rights to education and to information ${ }^{12}$.

\section{The role of experts}

Trustworthy decision making involves experts and is built on evidence. It is inevitable that we must sometimes act before scientific inquiry has led to anything like certainty ${ }^{13}$. This is especially so in this pandemic. There is often uncertainty surrounding key parameter values, relevant causal mechanisms and peoples' responses to novel events. To sensibly reason about these uncertainties, the public needs to be made aware of where these uncertainties arise and how they may be dealt with. Further, a transparent and frank dialogue between scientists, policy makers and the broader public can help combat the 'infodemic' of misinformation spreading on social media and interfering with attempts to rationally address COVID-19 $9^{14}$.

To justify any particular approach to dealing with these uncertainties, scientists must often appeal to ethical or political values concerning which risks are worth taking more seriously than others ${ }^{15}$. These value-laden decisions will affect not only what scientists take to be true, but also how scientists communicate their uncertainties ${ }^{16}$ and which measures are used to weigh and assess key outcomes of interest ${ }^{17}$. Science communication should hence prioritize communicating the nature of the value-laden decisions scientists must make, including what the stakes are and how different parties' legitimate interests are being assessed and weighed.

Scientists must be appropriately receptive to public feedback and to challenges. Science communicators should hence appreciate how input from the public on their findings can be legitimate and important and be receptive to bidirectional communication between citizens and scientific experts ${ }^{18}$.

Although these requirements of transparent and inclusive deliberation may appear demanding during a crisis, fulfilling them can contribute toward virtuous cycles of trust building and enhance implementation and adherence.

\section{Experiences from participatory innovations}

In the context of COVID-19, when hard policy choices and trade-offs are called for on a regular basis, it is important to set up systems that can provide for open and inclusive decision making in an institutionalized manner rather than as ad hoc efforts.

Experimentation with inclusive and deliberative decision-making processes provides useful guidance on how public deliberation can be designed to meet the requirements of a fair decision-making process in the context of the pandemic ${ }^{19}$. A plethora of mechanisms have been introduced across the globe in recent years to improve the quality and legitimacy of public decision making (see Box 2). Research has found that these tools, when carefully set up and implemented, have proven useful and robust in ways that are promising for the type of decision making called for in response to COVID-19 and for future health crises, involving value-based questions and complex trade-offs ${ }^{20}$.

Three types of inclusive, deliberative and participatory institutions are highly relevant in this context:

(i) Inclusive deliberative bodies that are set up to include relevant voices and produce well-considered advice. They may consist only of randomly selected citizens or also include experts, stakeholders and/or politicians. Some are ad-hoc citizens' assemblies, and others are permanent citizen panels that are set up to engage with new issues as they evolve or advisory councils with expertise in a particular area. Such deliberative bodies, when properly constituted, can be particularly useful for reaching more trustworthy and legitimate decisions on difficult ethical questions and complex trade-offs.

(ii) Hearings are set up in many countries to gather relevant insights from experts and stakeholders on draft legislation and policy. Advantages of these processes are that, particularly where already mandated, they are closely linked to formal decision making and have the potential to inform and spur public debate and to generate legitimacy for decisions with interested stakeholders. Most importantly, they can enhance the deliberative quality of governments and legislatures by 
expanding the points of view and interests considered. Hearings do not, however, produce an inclusive deliberated output as the participants in hearing processes do not jointly deliberate hard ethical issues and trade-offs. In most cases, institutionalized hearings are not open to the general public. Mandated consultations with indigenous peoples, set up to protect their autonomy and rights, could be extended to COVID-19 related decisions, in which indigenous groups are particularly vulnerable ${ }^{21}$.

(iii) Open, self-selective public participation mechanisms are designed to ensure that everyone, in principle, can make their voice heard. These can take a variety of forms, including deliberative town halls and village or municipality meetings that can be face to face or online via 'virtual democracy platforms'; radio and television call-in shows, calls for petitions and crowdsourcing of legal provisions, guidelines and policies. These mechanisms are often set up to harvest participatory input and make it available for decision makers, with efforts to show how it is taken into account in decision making. A common criticism of these mechanisms is that they are more often used by those with most resources, and they are not usually set up to ensure that the views of the most vulnerable are enabled or represented ${ }^{19}$.

These are not alternative mechanisms. They serve complementary purposes and are often combined. These mechanisms can serve as independent channels of input into legislative and policy processes, or deliberative bodies can be embedded in broader public participation mechanisms.

\section{Concluding remarks}

Evidence from before COVID-19 shows that deliberative decision making that is inclusive, transparent and accountable can contribute to more trustworthy and legitimate decisions on difficult ethical questions and political trade-offs. To institute and broaden deliberative processes should therefore be a priority in the context of pandemic response and in anticipation of future heath crises. In the short term, it can build legitimacy and support for hard decisions that need to be made in response to the pandemic and prevent further erosion of trust. In the longer term, it can contribute towards virtuous cycles of trust-building and more effective policies.

\section{Ole F. Norheim (D) 1,2四,}

Joelle M. Abi-Rached ${ }^{3,4}$, Liam Kofi Bright ${ }^{5}$, Kristine Bærøe (D)', Octávio L. M. Ferraz', Siri Gloppen (D) 7 and Alex Voorhoeve (D) 8,9 ${ }^{1}$ Bergen Centre for Ethics and Priority Setting, Department of Global Public Health and Primary Care, University of Bergen, Bergen, Norway. ${ }^{2}$ Department of Global Health and Population, Harvard T.H. Chan School of Public Health, Boston, MA, USA. ${ }^{3}$ Department of Geography and Territories, École Normale Supérieure, Paris, France. ${ }^{4}$ Medialab, Sciences Po, Paris, France. ${ }^{5}$ Department of Philosophy, Logic, and Scientific Method, London School of Economics, London, UK. ${ }^{6}$ Transnational Law Institute, The Dickson Poon School of Law, King's College London, London, UK. ${ }^{7}$ Centre on Law and Social Transformation, Department of Comparative Politics, University of Bergen, Bergen, Norway. ${ }^{8}$ Department of Philosophy, Logic, and Scientific Method, London School of Economics, London, UK. ${ }^{9}$ Departments of Applied Economics and Philosophy, Erasmus University Rotterdam, Rotterdam, Netherlands.

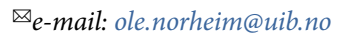

Published online: 18 December 2020 https://doi.org/10.1038/s41591-020-01204-6

\section{References}

1. Alwan, N. A. et al. Lancet 396, e71-e72 (2020)

2. Fontanet, A. \& Cauchemez, S. Nat. Rev. Immunol. 20, 583-584 (2020).

3. Brazeau, N. et al. https://doi.org/10.25561/83545 (2020).

4. Office for National Statistics UK. https://www.ons.gov.uk/ peoplepopulationandcommunity/birthsdeathsandmarriages/ deaths/bulletins/deathsinvolvingcovid19bylocalareasand deprivation/deathsoccurringbetween 1 marchand 31 july 2020 (2020).

5. World Bank. https://www.worldbank.org/en/news/pressrelease/2020/10/07/covid-19-to-add-as-many-as-150-millionextreme-poor-by-2021 (2020).
6. Gutmann, A. \& Thompson, D.F. Why Deliberative Democracy? (Princeton University Press, Princeton, NJ, 2004).

7. Daniels, N. \& Sabin, J.E. Setting Limits Fairly: Can We Learn to Share Medical Resources? Second Edition (Oxford University Press, Oxford, 2008).

8. Miller, D. T. Annu. Rev. Psychol. 52, 527-553 (2001)

9. Tyler, T. R. Аnпu. Rev. Psychol. 57, 375-400 (2006).

10. Dryzek, J. S. et al. Science 363, 1144-1146 (2019).

11. Jansen, M. P. M., Baltussen, R. \& Bærøe, K. Int. J. Health Policy Manag. 7, 973-976 (2018).

12. UN Office of the High Commissioner for Human Rights. Equal Participation in Political and Public Affairs. Resolution Adopted by the Human Rights Council on 30 September 2016. United Nations A/HRC/RES/33/22. (The Human Rights Council, Geneva, 2016)

13. Heesen, R. Philos. Stud. 172, 2299-2313 (2015).

14. Lewandowsky, S. et al. Technology and Democracy: Understanding the Influence of Online Technologies on Political Behaviour and Decision-Making. (Publications Office of the European Union, Luxembourg, 2020).

15. Ward, Z. B. On value-laden science in Stud. Hist. Philos. Sci. Part $A$ (in the press)

16. Steele, K. Philos. Sci. 79, 893-904 (2012).

17. Schroeder, S. A. Public Health Ethics 10, 176-187 (2017).

18. Kitcher, P. Science, Truth, and Democracy (Oxford University Press, Oxford, 2003).

19. Smith, G. Democratic Innovations: Designing Institutions for Citizen Participation (Cambridge University Press, Cambridge, 2009).

20. OECD. Innovative Citizen Participation and New Democratic Institutions: Catching the Deliberative Wave (OECD Publishing, Paris, 2020); https://doi.org/10.1787/339306da-en

21. Charlier, P. \& Varison, L. Lancet 396, 1069-1070 (2020).

22. Open Government Partnership. https://www.opengovpartnership. org/wp-content/uploads/2019/08/Global-Report_Health.pdf (Accessed November 5. 2020).

23. Participedia. A global network and crowdsourcing platform for researchers, educators, practitioners, policymakers, activists, and anyone interested in public participation and democratic innovations https://participedia.net (accessed November 124, 2020)

24. Sénat. Commission d'enquête pour l'évaluation des politiques publiques face aux grandes pandémies à la lumière de la crise sanitaire de la COVID-19 et de sa gestion http://www.senat.fr/ commission/enquete/gestion_de_la_crise_sanitaire.html (2020).

25. National Academies of Sciences Engineering and Medicine. https://www.nationalacademies.org/our-work/a-frameworkfor-equitable-allocation-of-vaccine-for-the-novel-coronavirus/ announcement/public-comment-opportunities (2020).

26. Conselho National de Saúde. http://conselho.saude.gov.br/ recomendacoes-cns (2020).

27. Dimitrova, A. https://www.themayor.eu/sk/grenoble-turnsto-citizens-for-the-handling-of-the-health-crisis (2020).

28. Abi-Rached, J. M. et al. https://www.arab-reform.net/publication/ towards-a-zero-covid-lebanon-a-call-for-action/ (2020).

29. Lucienne, M., Odiaua, I. \& Yamouri, N. https:// blogs.worldbank.org/youth-transforming-africa/ senegals-youth-offers-inspiring-creativity-fight-covid-19 (2020). 30. Independent SAGE. https://www.independentsage.org (2020).

\section{Acknowledgements}

This work was supported by Trond Mohn Foundation (BFS2019TMT02) and Norad (RAF-18/0009) through Bergen Centre for Ethics and Priority Setting (BCEPS; project number 813 596).

\section{Competing interests}

The authors declare no competing interests. 